Gerhard Sadler

Ordnungs- und Polizeieingriffsrecht 



\section{Ordnungs- und Polizeieingriffs- recht}

ASOG, Bundes- und Länderrecht Mit 66 Musterbescheiden

Von

Dr.jur. Gerhard Sadler

Leitender Magistratsdirektor, Berlin 
CIP-Kurztitelaufnahme der Deutschen Bibliothek

Sadler, Gerhard:

Ordnungs- und Polizeieingriffsrecht: ASOG,

Bundes- $u$. Länderrecht; mit 66 Musterbescheiden/ von Gerhard Sadler. - Berlin: Schweitzer, 1980.

ISBN 3-8059-0578-5

(C) 1980 by J. Schweitzer Verlag, Berlin

Alle Rechte, insbesondere das Recht der Vervielfältigung und Verbreitung sowie der Übersetzung, vorbehalten. Kein Teil des Werkes darf in ịgendeiner Form (durch Photokopie, Microfilm oder ein anderes Verfahren) ohne schriftliche Genehmigung des Verlages reproduziert oder unter Verwendung elektronischer Systeme verarbeitet, vervielfältigt oder verbreitet werden.

Druck: Karl Gerike, Berlin. - Bindearbeiten: Lüderitz \& Bauer Buchgewerbe GmbH, Berlin.

Printed in Germany. 